\title{
'Language is only a tool': Japanese expatriates working in China and implications for language teaching
}

Ryuko Kubota

Correspondence: ryuko.kubota@ubc. ca

Department of Language and Literacy Education, Faculty of Education, University of British Columbia, 2034 Lower Mall Rd. Vancouver, BC V6T 1Z2, Canada

\begin{abstract}
Drawing on a qualitative case study, this article questions two prevailing assumptions: that English is a universal lingua franca and that English proficiency is indispensable for transcultural work. The study involved Japanese manufacturing companies with subsidiaries in China and investigated the language use of Japanese expatriates and Chinese office workers as well as the views of participants (including managers in Japan) about competencies deemed important for overseas work. Interview data revealed that the major languages used were Japanese and to a lesser extent Mandarin. Although English proficiency was deemed useful, the primary importance was placed on the "ability to communicate" supported by communicative and foundational dispositions along with cultural knowledge. These findings pose a challenge for critiquing neoliberal underpinnings.

Keywords: English as a lingua franca, Foreign language learning, Globalization, Language in the workplace, Multilingualism, Neoliberalism
\end{abstract}

\section{Introduction}

In China, Japanese, rather than English, is used [in the workplace] in many cases; but there, the language needed is basically not Japanese or English but Chinese. ... What's necessary is for the Japanese (expatriates) to learn Chinese.

Workers, who are capable of doing their job well in Japan, can manage [language demands] once they are overseas. Basically, we don't consider language skill as the goal. ... in schools, the goal is to learn [English] grammar and vocabulary through tests and get the perfect score on a paper exam. ... But at work, the goal is to accomplish your task whether in Japan or abroad. We consider language skill as just one of the tools. (both translated from Japanese)

These are statements made by one of the present study's interviewees, a manager of the personnel department of a major Japanese manufacturing company. These comments question common beliefs - that English serves as a universal lingua franca and that contemporary work categorically demands high English proficiency. The first

\section{Springer}

(c) 2013 Kubota; licensee Springer. This is an Open Access article distributed under the terms of the Creative Commons Attribution License (http://creativecommons.org/licenses/by/2.0), which permits unrestricted use, distribution, and reproduction in any medium, provided the original work is properly cited. 
belief supports the growing scholarly interest in the role of English in the globalized world, whereas the second one reflects the neoliberal ideology that emphasizes the development of so-called soft skills as part of human capital in the knowledge economy (Block et al. 2012; Kubota 2011; Park 2011; Urciuoli 2008). These beliefs drive the current trend of foreign language education in the non-English-speaking world, emphasizing learning English and measuring linguistic skills by standardized tests such as IELTS (International English Language Testing System), TOEIC (Test of English for International Communication), and TOEFL (Test of English as a Foreign Language). While the spread of English is an undeniable fact, other lingua francas exist and function in many social settings (Mufwene 2010). Furthermore, research on language and global mobility has revealed diverse linguistic repertoires that are not aligned with bounded standard language (Blommaert 2010; Blommaert et al. 2005).

Although proficiency in an additional language is important in transnational work, employers typically look for workers who are not linguists but those with strong professional competency in addition to language skills (Bloch 1995). In fact, an overemphasis on teaching language skills may neglect other skills and dispositions required for the globalized workplace. Assumptions about English and linguistic skills can be critically explored by examining the language use of transnational workers who are native speakers of a language other than English working in a non-English-dominant world, their experiences of linguistic and non-linguistic challenges, and their views about the knowledge, skills, and dispositions required in transnational work. Seeking intersections of the inquiries into English as a lingua franca, language in the workplace, and foreign language education, this article reports a qualitative case study that investigated these questions by focusing on Japanese expatriates in China and Chinese co-workers in the manufacturing sector.

\section{Teaching English, skills, and ideologies}

The assumption that English is an international lingua franca connecting people from diverse linguistic backgrounds underpins recent scholarship in language education, including English as an international language (e.g., McKay and Bokhorst-Heng 2008; Sharifian 2009), world Englishes (e.g., Kachru and Smith 2008; Kirkpatrick 2007), and English as a lingua franca (ELF) (e.g., Jenkins et al. 2011; Seidlhofer 2011). This assumption is also reflected in the increased emphasis on teaching English as a foreign language in many parts of the world. In Japan, for example, strong trends for teaching and learning English in both public and private sectors are observed in introducing English to the primary school curriculum (Butler 2007; Butler and Iino 2005; Kubota 2011, 2003); in the popularity of English language tests, especially TOEIC for career and academic purposes; and even in public debates on making English an official language (Kawai 2007; Matsuura et al. 2004). Many of these developments are influenced by a series of recommendations for education made by Japanese business associations (Kubota 2011). Moreover, English use is institutionalized in the business sector, as seen in the English-only policy enforced by large Japanese businesses like Rakuten and UNIQLO. Conversely, the spread of English has been criticized from the perspective of linguistic imperialism as it reinforces inequalities between English speakers and nonEnglish speakers, increases the superiority of native speakers of English, and threatens minority languages (e.g., Phillipson 2009; Skutnabb-Kangas 2000). 
Many of these discussions about English are based on the premise that English has become the most natural and viable choice for intercultural communication and therefore it is universally used for global communication. However, this assumption has been questioned. From a sociolinguistic point of view, it is estimated that more than threequarters of the world population is non-English-speaking (Graddol 2006) and the major lingua franca among transnational nonelite migrant workers outside of Englishdominant countries is often the dominant language of the host country rather than English (Gottlieb 2008; Kubota and McKay 2009; Mufwene 2010). A qualitative study on elite Russian workers in Germany revealed that English was not universally used in all situations in the workplace. While some used English, it was only for work-related topics; some Russian job seekers were disadvantaged for not speaking German; and moreover some used their native language, Russian, exclusively (Amelina 2010). A study of Japanese companies operating in China revealed that, unlike in such countries as Malaysia and the Philippines where English is typically used as a lingua franca, Japanese expatriates experience the need for a working knowledge of Mandarin (Nebashi 2007).

Even in English-dominant countries such as Canada, the United Kingdom, and the United States, immigrant workers do not necessarily use English in the workplace; rather, they often use their native language or learn other immigrants' languages for workplace interaction (Block 2007; Duff et al. 2000; Goldstein 1997; Harper et al. 1996; Kramsch and Whiteside 2007, 2008; Norton 2000). Indeed, frequent reference to English as an international lingua franca in scholarly and educational contexts reinforces the truth effect of this assumption. Moreover, an intensive focus on English in academic, educational, and public policy discourses could undermine the importance of learning other languages.

But what level of linguistic competence in any language is needed for transnational work? The above-mentioned study in Germany (Amelina 2010) indicates that language used in a multilingual workplace may display very specialized linguistic forms depending on the purpose and the language user's repertoire. It may indeed demonstrate "truncated multilingualism," which is "linguistic competencies which are organized topically, on the basis of domains or specific activities" (Blommaert et al. 2005, p. 199). The linguistic competence necessary for specific workplace communication might be quite different from what is typically taught in language classrooms which presumes ability of the complete spectrum of the standard variety of a language.

The assumption about English as an international language is closely related to the neoliberal notion of human capital or abilities deemed necessary for the knowledge economy (Heller 2003; Urciuoli 2008; Williams 2010). As an important aspect of human capital, English competence is deemed essential for career opportunities and upward socioeconomic mobility (Kubota 2011; Park 2010, 2011). Recent quantitative research on language economics concludes that language skills are indeed positively related to earning, but this may apply more to men than to women and all data come from North American and European settings involving European languages (Grin et al. 2010). Moreover, companies do not necessarily prioritize pre-existing skills in English (or another language) for employment or overseas work assignment (Kubota 2011), which might be related to practical constraints such as cost effectiveness arising from the recruitment of competent employees (Grin et al. 2010). The role of English competency for work in Asian settings requires further investigation. 
Issues of multilingualism in the workplace have been studied within applied linguistics from various conceptual and methodological perspectives, such as pragmatics in workplace communication (i.e., politeness and various functions such as complaints, directives, and apologies); ethnography for investigating language choice, literacy practices, identity, and the role of English instruction in the workplace; and issues of power, ideology, and discrimination in gate-keeping encounters such as job interviews and skills testing (see Duff 2008 and Roberts 2007 for syntheses). Other studies focus on gender in workplace communication (e.g., Holmes 2003) or are situated in the inquiry area of English for specific purposes and investigate how non-native English speakers use English in various business contexts such as emailing, business meetings, and specific work (e.g., Forey and Lockwood 2007; Rogerson-Revell 2007, 2008; Wozniak 2010). These studies, however, are predominantly situated in English-dominant societies where communication in English is assumed.

Another interdisciplinary area of inquiry is business discourse, which involves linguistics, communication studies, organization studies, and international management, and investigates how workers and business institutions, including multinational corporations, accomplish tasks through oral and written communication (Bargiela-Chiappini 2009). Although English is still a major topic of discussion, this inquiry area tends to be more international and the use of other languages is examined. Within the domain of international management, for instance, studies on multinational corporations generally found that although English is typically chosen as a common corporate language, other languages do play the role of either common or operational language and language policy is sometimes left ambiguous due to affective and political consequences within the workplace (Piekkari 2009). With regard to the role of language proficiency in personnel overseas assignments, Piekkari (2008) concludes that "more emphasis tends to be placed on professional competence rather than language competence per se" (p. 132), which corresponds to the views of Japanese managers (Kubota 2011).

Despite such scholarship in multiple disciplines, little is known, as Tanaka (2009) points out, about communication in the transnational workplace in non-English -dominant countries in Asia, where, for instance, Japanese workers interact with other Asian workers. An investigation of actual language use and competencies viewed as important by focusing on the transnational workplace would provide useful insights into teaching and learning for preparing future citizens in the globalized society. This article specifically aims to fill the scholarly gaps and explores implications for language education.

This article focuses on six major Japanese manufacturing companies and investigates through interviews the language use of current and former Japanese expatriates and local Chinese office workers in three subsidiaries in China. It also examines the views of interviewees, including managers at the headquarters in Japan, about knowledge, skills, and dispositions deemed important for overseas work. It specifically investigates the following questions: What languages do Japanese expatriates use in the workplace? What other knowledge, skills, and dispositions do the Japanese company managers, expatriates, and local workers think necessary? I approach this research from a critical perspective, questioning taken-for-granted assumptions to transform the status quo. However, as discussed later, corporate business rests in the neoliberal system and thus this research raises difficult questions. 


\section{Methodology}

Adopting a qualitative approach, I conducted interviews with employees of six major manufacturing companies in Japan and three subsidiaries in China (two in a major city and one in a midsized city), which were associated with two of the six parent companies. Interviews in Japan involved Japanese managers or those who were familiar with personnel policies ("managers" hereafter) about expatriates and former expatriates in China. Interviews in China involved current Japanese expatriates and Chinese office workers. The interviews took place in Japan in 2010 and in China in 2011. All interviews were conducted in a faceto-face semi structured format in Japanese arranged individually or in a small group.

Of many industries in Japan, I chose the manufacturing sector as a focus since it has the largest overseas expansion, constituting approximately $42 \%$ of all Japanese industries operating overseas (Toyo Keizai 2009). China was chosen as a site of investigation because it is a non-English-dominant country and the top destination of Japanese companies' overseas expansion. In 2008, China hosted a total of 5,017 subsidiaries set up by 2,474 Japanese companies, which constituted $23 \%$ of all the Japanese subsidiaries abroad (Toyo Keizai 2009).

A contact person at each company was identified through personal connections. The contact person either arranged interviews or agreed to be interviewed. The interviews with managers were conducted either in a one-on-one or group format, whereas those with former expatriates were conducted individually. At two headquarters, interviews with former expatriates were attended by the contact person. The contact persons were also included in the study as managers since they participated in the interviews. One former expatriate was working at a factory outside of Tokyo and was interviewed separately. Some interviewees in Japan had experienced being both a manager and an expatriate in China and/or other foreign countries. Their accounts from both perspectives were included in the data.

Visits to subsidiaries in China were arranged via the headquarters in Japan. Due to lack of resources for interpretation, I had requested that Chinese employees speak either Japanese or English. All Chinese interviewees spoke in Japanese. All interviews with Japanese and Chinese participants were one-on-one except for one joint interview with two Chinese employees. At two subsidiaries, a brief tour of the workplace was arranged, allowing me to observe an office floor and a production floor.

All in all, interview accounts come from the following three groups: 13 Japanese managers at six Tokyo headquarters, 10 expatriates ( 6 former and 4 current), and 6 Chinese local office employees (see Table 1). Of the expatriates, 5 worked for Company A (3 former and 2 current), 4 worked for Company B (2 former and 2 current), and 1 former expatriate worked for Company C. The former expatriates worked in China for 1 to 5.7 years with an average of 4.4 years, whereas the current expatriates had been working in China for 1 to 9 years with an average of 3.7 years. All Japanese interviewees were male, except for 2 female managers who attended two interviews in Tokyo. The male dominance reflects the typical employment pattern of major Japanese manufacturing companies. One manager was a long time employee originally from China with a degree from a Japanese university. Of 6 Chinese employees, 2 were female and 4 were male.

Interview questions for managers included: What criteria are used for selecting employees for overseas assignments? What cultural and linguistic challenges do expatriates face? What kinds of language skills are important? What abilities and 
Table 1 Participants

\begin{tabular}{lllll}
\hline Company & Manager & Former expatriate & Current expatriate & Local staff \\
\hline A & AM1, AM2, AM3 & AF1(AM1), AF2, AF3 & AC & AL1, AL2* \\
B & BM1, BM2, BM3* & BF1, BF2 & BCSubX1, BCSubX2 & BLSubX1 \\
& & & & BLSubX2* \\
& & & BCSubY & BLSubY1 \\
& & & - & BLSubY2 \\
C & CM & CF(CM) & - & - \\
D & DM1, DM2* & - & - & - \\
E & EM & - & - & - \\
F & FM & - & & \\
\hline
\end{tabular}

Note: $\mathrm{A}$ to $\mathrm{G}$ denotes companies. Asterisks denote female. AF1(AM1) and $\mathrm{CF}(\mathrm{CM})$ indicate that these two individuals represent both manager and former expatriate.

qualifications are required for working overseas? For current and former expatriates, I asked about their experience abroad in addition to their personal and linguistic background. Other questions included: What language(s) do/did you use for what types of tasks in the workplace? What cultural and linguistic challenges do/did you experience? How do/did you overcome them? What knowledge, skills, attitudes, and awareness do you think are important for working overseas? For Chinese employees, I asked about their personal and linguistic background and the following questions: What language(s) do you use for what types of tasks with Japanese expatriates? What cultural and linguistic challenges do you experience with the expatriates? How do you overcome them? Each interview lasted between 15 and 75 minutes with an average of 42 minutes. Each interview was audio-recorded (except for one participant who declined) and transcribed later. Content analysis of the data was performed with an interpretive lens by synthesizing the responses and identifying common themes.

Before presenting the findings, limitations of this study should be noted. First, due to a difficulty of accessing corporate sites for research (Bargiela-Chiappini 2009; Roberts 2007), only a small number of participants were involved and only interview data were available. Actual workplace communication would offer richer data. Second, although this study focused on the manufacturing sector, some of the companies (companies D and F) have a strong information technology service section as well. The diverse nature of business for large businesses, coupled with the difficulty in access, made it rather challenging to identify a homogeneous group of participants. Third, the sample seemed to lack diversity as the participants were selected by the contact persons. The interviewees' overall proactive tone, as exemplified in some Japanese expatriates' reference to other expatriates with less positive attitudes toward China, indicates that they were distinctive employees from the contact persons' perspective. Finally, due to lack of resources, interviews with Chinese employees were not conducted in Mandarin. Multilingual data collection would provide more comprehensive data in future research. The following findings should be tempered by these limitations.

\section{Findings}

\section{Language use}

When I mentioned that one focus of my investigation was language use in the workplace in China, most managers stated that China differs from other countries in that 
Japanese and Mandarin, ${ }^{1}$ rather than English, are mostly used (cf. Nebashi 2007). As indicated below, the prevalent use of Japanese and Mandarin might be related to the proximity of the written systems and a legacy of Japanese colonialism. Some managers mentioned that the language depends on the nature of the work. Interviews with expatriates paralleled such comments; of the ten former and current expatriates, only three mentioned that English was the major language for work. The responses from other expatriates indicated that, although there were some individual and corporate differences, the major languages used between the expatriates and Chinese local employees or clients were Japanese and to an extent Mandarin in oral and written communication.

Language use is obviously influenced by one's language proficiency. Although all expatriates used Mandarin with varied self-reported levels of proficiency, three (AF1, AF2, BF2) commented that their Mandarin proficiency was very limited. Of them, two (AF1, AF2) stated that they used English $70 \%$ to $80 \%$ of the time and Japanese for the rest, whereas one (BF2) said that Japanese was the main medium of communication. In contrast, three expatriates (BF1, BCSubX2, CF) learned Mandarin at a Chinese university for approximately a year (one had studied as an undergraduate student and two had been sent by their company) and considered themselves to be fluent in spoken and written Mandarin. Of the three, two used Mandarin as the major medium of workplace communication, whereas one commented that Japanese was used more often than Mandarin.

The remaining four expatriates (AF3, AC, BCSubX1, BCSubY) used Mandarin with varied frequency. One (AF3) commented that he used mostly Japanese in the beginning but toward the end of his stay, he was using about 40\% Japanese and 60\% Mandarin for oral communication, whereas he used Japanese and English for written communication. Another expatriate, who dealt with local sales agents (BCSubX1), said that he used mostly Japanese for oral communication in his office, whereas he handled Mandarin email messages sent directly from Chinese sales agents. Asked what he would do if he could not understand, he said, "I can understand from Chinese characters and [Arabic] numerals because the content is predictable." An interpreter accompanies him on business trips within China, but he occasionally makes simple speeches in Mandarin. Another expatriate, who had previously lived in the United States (BCSubY), was surprised to find out that English was not used at all in his workplace in China. He began learning Mandarin seriously and became able to use it to some extent for email and spoken communication. Conversely, another current expatriate (AC) stated that although he was learning Mandarin, he used mostly English since his work involves sales clients outside of China.

Expatriates' frequent use of Japanese is supported by the fact that many Chinese office employees, as much as perhaps $50 \%$, had a varied range of Japanese proficiency. The subsidiaries actively hire Chinese workers with Japanese proficiency and they encourage Chinese employees to learn Japanese once they are hired. One former expatriate (BF1) explained that while he was in China, Chinese employees with English proficiency increasingly left for Western companies, making his workplace more bilingual in Japanese and Mandarin. Following the Japanese corporate tradition, which prioritizes employees' on-the-job training for long-term employment, the company began to support Chinese employees' Japanese language learning. This in turn reduced the necessity to compete with Western companies for recruiting workers with similar 
competencies. One Chinese interviewee (AL2) also mentioned that although English proficiency was deemed important for Chinese office employees and many already had functional English skills, knowing Japanese would provide them with a competitive edge in the current tough job market.

The Chinese interviewees obviously represent such a profile. All studied Japanese formally. Four interviewees (AL2, BLSubX1, BLSubY1, BLSubY2) studied in Japan in the 1980s and/or 1990s, when learning Japanese was popular. One interviewee (AL1) lived in Japan for 11 years; originally from Taiwan, he had moved to Japan as an adolescent, completed a master's degree in engineering in Japan, and was hired by the current company in Japan. In contrast, another interviewee (BLSubX2), who was younger than the others, majored in Japanese in China. She had only traveled to Japan once on business. All of the Chinese interviewees used Japanese for oral and written communication. Of the six, the Taiwanese multilingual interviewee used English as well. He made a comment that represents one nature of communication that applied to Japanese expatriates as well:

Ryuko: Is Japanese currently a medium when you communicate with Japanese expatriates?

AL1: Yes, it is.

Ryuko: How about email?

AL1: That's Japanese too. I use a different language depending on whom I communicate with. For example, I use Chinese with local employees, Japanese with expats, and English when I have inquiries from abroad.

Paralleling the above comment, bilingual or multilingual expatriates also used different languages depending on the interlocutors' linguistic repertoire. Yet, the communication can be hybrid. For both expatriates and local employees who use their second language with varied levels of proficiency, language mix is a typical consequence. One former expatriate (AF2) reflected on the common practice of language mix which included Chinese employees' use of Japanese slang and his mixing of Mandarin.

Written communication did not completely overlap oral communication. According to the expatriates, their email communication with Japanese colleagues or clients was in Japanese. When email communication involved multiple recipients, a message was sometimes translated into or dictated in Mandarin, depending on the message's importance and the recipients. Conversely, expatriates handled routine or non-critical email communication in Mandarin by using such strategies as guessing the meaning from the Chinese characters and numerals or writing in Japanese by using as many Chinese characters as possible, although the effectiveness of especially the latter strategy is unclear. These strategies are made possible because Japanese and Mandarin share logographs, though their forms or meanings are not always identical.

The three expatriates who used English as a major medium of oral communication also used English for email communication. One current expatriate (AC), manager of a sales coordination department whose work mostly involved sales-related business outside of China, commented that he encouraged Chinese employees to use English in order to make communication transparent to him and other Japanese employees. Another former expatriate (AF3), who shifted from Japanese to Mandarin in oral 
communication during his stay, commented that email communication was mostly conducted in English.

It seems that the language choice and use depends on the nature of the work, the linguistic repertoire of the interlocutors, individual linguistic subjectivity, and possibly the culture of each workplace. As previously mentioned, when the work involves communicating with people outside of China or English-speaking Chinese, English tends to be used. Within the office, depending on the linguistic repertoire of the participants, the language of a meeting can be Japanese, Mandarin, or English. Furthermore, many interviewees agreed with the following statement of a former expatriate:

The closer you get to the worksite where our machines operate, the more necessary the local language becomes. (BF1)

For one current expatriate, an engineer who works for the product support department and often travels to solve technical problems, speaking Mandarin is essential. For the production floor, most workers are not Japanese or English speakers; they tend to use their local language, dialect of Chinese. For Japanese engineers to communicate with production floor workers, they need Mandarin proficiency or an interpreter. During a brief factory tour, I saw a Japanese engineer instructing a group of Chinese workers via a Chinese interpreter. All the bulletin boards were mostly displayed in Mandarin with some Japanese, indicating that some of the posters (e.g., safety information) were translated from Japanese originals.

The choice of language also depends on the nature of the task. If the task does not require sophisticated language, a second language can be used. Conversely, if the task is complicated, translation and interpretation comes into play. As one manager (FM) explained, technical work like presenting new technology to local workers and clients typically does not involve complicated negotiation and thus minimum language proficiency usually suffices. Conversely, detailed communication requires a translator or interpreter, usually local Chinese employees or Japanese employees who are proficient in Mandarin and hired locally. However, language specialists per se are few-they might initially be hired for communication purposes but they are trained to acquire other work skills. This echoes the career requirement that typically goes beyond being a "pure "linguist"” (Bloch 1995). Overall, many expatriates are compelled to use language(s) other than Japanese with varied levels of sophistication. This raises a set of questions posed by one former expatriate (BF1):

When we say someone can speak a language, like English, what does it mean? At which level, from a professional point of view, someone is proficient? ... When I'm asked "Do you speak Mandarin?" I say "Yes," but I wonder what it takes to say I can speak it. Is it being able to serve as an interpreter? Or is it being able to say greetings and interact?

These questions seem to signify truncated repertoires that are partial and specialized and yet functional in a workplace (Blommaert 2010; Blommaert et al. 2005). The blurred definition of language proficiency for business purposes calls into question the appropriateness of conventional goals for teaching foreign languages. 
One interesting issue is a possible link between language choice and workplace-specific practice or individual subjectivity. The four expatriates who used mostly English for email communication worked for the same company (AF1, AF2, AF3, AC). Language choice and use might be part of corporate practices unique to each workplace, although choosing a common language is often an emergent process (Piekkari 2009). It is also worth noting that two of these four expatriates used to work in a subsidiary in Singapore where English was predominantly used. One former expatriate (AF2) stated that he had few opportunities to use Mandarin in his workplace because his local co-workers spoke English or Japanese. His following comment was followed up by a manager:

AF2: ... It [language choice] depends on the section or environment. For example, in the production department, people don't speak English, so they have to communicate in Mandarin ... If you happen to speak some English, you try to use it. But if you can't speak English well, you'd try to communicate in Mandarin from the get-go and you become good at it quickly-I was the former case.

AM3: Being able to speak English can be good or bad in the Chinese context. People naturally rely on English, so ... if a [Japanese] worker who can only speak Japanese is sent there, then what to be learned is Mandarin. These people tend to make better progress in learning Mandarin.

Some expatriates with English-speaker subjectivity apparently shun learning the local language in an ELF environment.

In sum, Japanese and, to some extent, Mandarin are major common lingua franca in the office space for Japanese expatriates but English is also used for work involving overseas clients and English-speaking Chinese clients or mainly for written communication. The orthographical proximity between Japanese and Mandarin allows written communication in both languages. The closer the work is related to the local contexts, the more the local language is used. Overall, language choice depends on the linguistic repertoires of the interlocutors, the nature of work, and perhaps individual subjectivity.

\section{Skills, knowledge, and dispositions required for expatriates}

Interviewees acknowledged the importance of language skills, especially English in general and Mandarin for working in China. One manager (FM), who regularly participated in meetings with global partners, emphasized the importance of English. However, both managers and expatriates shared a consensus that transcultural communicative and cultural competence and dispositions were as or more important. Asked about the criteria for selecting expatriates, one manager (AM2) stressed that the ultimate goal is often misunderstood. He said:

What's clear is that it's not about language skills-what matters is whether a person can do the work or has motivation to do it. That's it. Someone who can't do the job or has no motivation can't function abroad even if he can speak a foreign language.

His next comment provided the opening quote of this article, in which he contrasted schools and workplaces and pointed out that in the work culture language proficiency 
is considered to be "only one of the tools" to accomplish the ultimate goal. This view that prioritizes work competence over language proficiency and regards language as a tool or dôgu was shared by all managers, paralleling a previous study with smaller companies (Kubota 2011) as well as others (Bloch 1995; Piekkari 2008).

This issue is related to the corporate policy on TOEIC scores for hiring and promotion. Although all companies utilized TOEIC for hiring and promotion, they used scores only as supplementary information in making personnel decisions. In other words, lower scores alone do not justify candidate elimination. This is again because language skill is deemed complementary to work skills and managers generally believe, based on their past experiences, that those who are competent workers can manage language demands onsite. One current expatriate who received one year of Mandarin language training (BCSubX2) is a case in point: his company required a score of at least 500 on TOEIC, which he had failed to attain. Nonetheless, he said, "I wasn't concerned because I was convinced that I'd be OK once I actually lived abroad." Although he admitted that his current spoken English was very limited, he will probably do as well in an English-speaking environment as he had in a Mandarin-speaking context.

If language proficiency measured by a test may not be essential, then what is considered to be crucial? What the interviewees emphasized can be conceptualized in a broad stroke into two categories: (1) ability to communicate with associated knowledge and dispositions and (2) personal qualities. Figure 1 summarizes these components.

First, the ability to communicate includes communication strategies that overlap broadly defined strategic competence (Canale 1983) or "the ability to manage communication ... in order to achieve an intended interactional goal" (Nakatani 2005 p. 77). It is competence to convey messages in a concise, focused, and intelligible manner through written and oral modes of communication (e.g., drawing pictures, writing down, hitsudan [brush talk], whereby expatriates write key Chinese character(s) to convey or confirm intended meaning-see Hwang (2009), paraphrasing, exemplifying, using hand and body gestures, and using real objects. One former expatriate with Mandarin proficiency (BF1) commented that what worked for him was the ability to accommodate the situation and find ways to communicate, again signifying truncated repertoires. Thus,

... rather than people who know a lot of vocabulary, someone who can substitute with appropriate words in a particular situation might have higher komyunikêshon ryoku [ability to communicate]. ... Rather than communicating with appropriate vocabulary and grammar, what's necessary for us, I think, is the ability to convey meaning even without grammar.

Overall, the goal is "to communicate in a straightforward, simple, and clear mannersutorêto ni, shinpuru ni, kuria ni tsutaeru-and yet politely" (FM) in any language and acquiring strategic competence is deemed important to compensate limited linguistic resources shared by interlocutors.

Ability to communicate is supported by essential qualities, which were mentioned by interviewees and can be called communicative dispositions. They are divided into two categories: willingness to communicate and mutual accommodation (cf., Lippi-Green 2012; Nieto and Bode 2008). First, interviewees said that willingness to communicate 


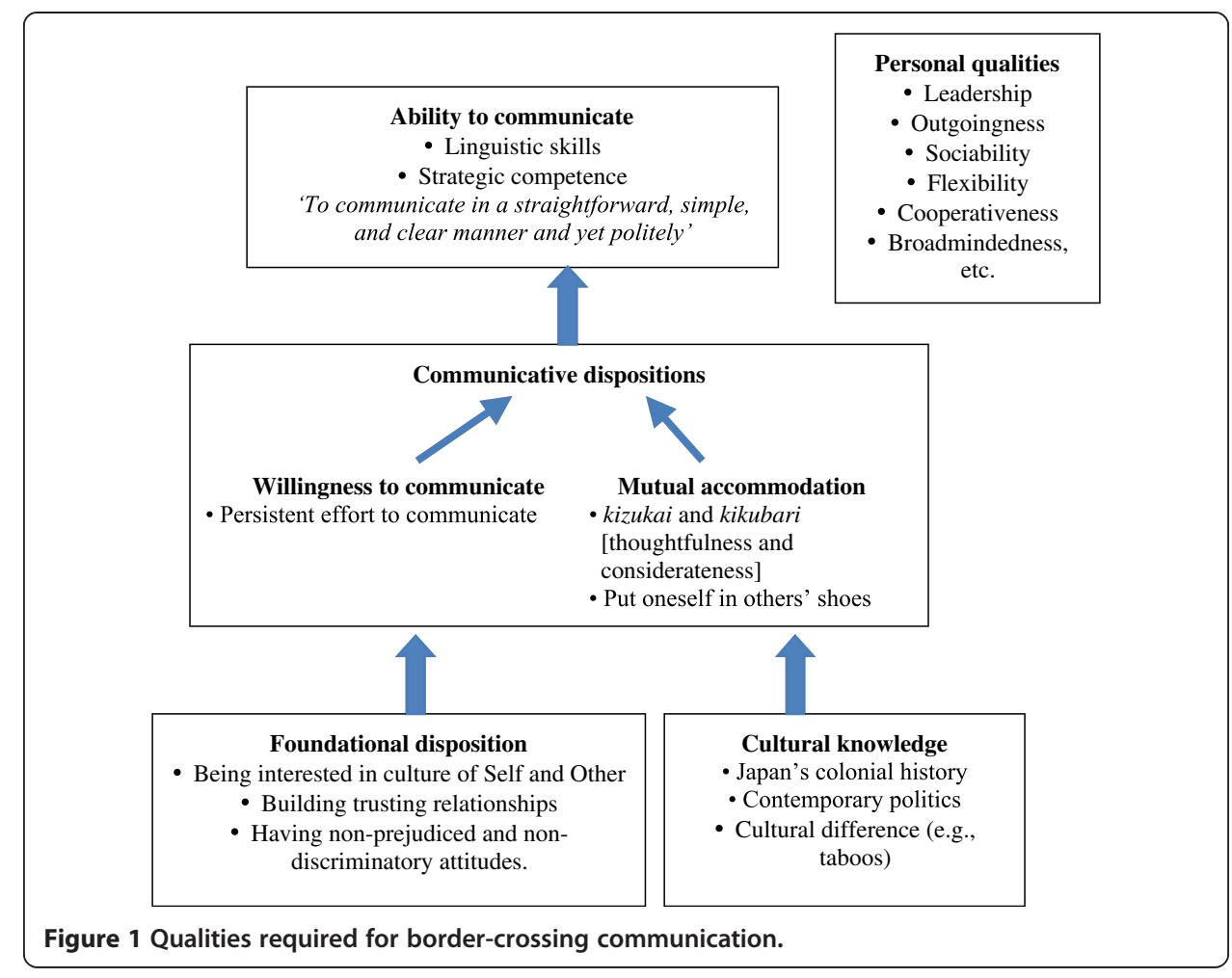

even with limited linguistic resources (AF2, BF1, CF) as well as persistent effort to communicate (AM1, CF) were essential. Reflecting on his experience of engaging in an internship in Turkey as a university student, a former expatriate (AF2) commented about communicating in English:

I really learned that it's not so much about how well you can speak the language but how to try to express yourself or listen to the other; and it's OK if you don't understand everything.

Second, interviewees' responses point to the importance of mutual accommodation. Specifically, dispositions such as kizukai and kikubari [thoughtfulness and considerateness] and efforts to be in the interlocutor's shoes (AM2, DM1, AF3, CF, BCSubX2, BCSubY); sincerity (BF1); respect (BLSubY2); and humbleness (BLSubY2) make communication a shared activity. The following comment by a local employee (BLSubY1) synthesizes these qualities:

We should put ourselves in the other person's shoes in order to understand each other better. Oftentimes people misunderstand each other when they don't make themselves understood but instead speak in ways that can be understood only by themselves.

These communicative dispositions are further supported by foundational dispositions and cultural knowledge. Foundational dispositions are attitudes and awareness necessary to build mutual trust. They include being interested in the culture and customs of 
the Other as well as the Self (AM2, EM, BCSubY), building one-on-one trusting relationship (AF3, AC, BCSubY), and having non-prejudiced and non-discriminatory attitudes (AM1, AM2, CF, BM1, BF1). These dispositions are represented in a reflection of one former expatriate (AF3) who worked in China for 5 years. During the first year, he had negative attitudes toward Chinese people; he overgeneralized their not keeping promises or schedules as "because this is China." But he realized that this attitude prevented him from working collaboratively with his Chinese colleagues and from enjoying his work. After observing and interacting with an older expatriate who had a more positive outlook, he eventually changed his attitudes. He commented:

After all, it is about interaction between people. So, if you hate the other person, your business would be over and your relationship beyond business would be over too. So, those who want to befriend people are more suited [for doing business overseas].

Expatriates' accounts need to be understood against the backdrop of the political and historical animosity between China and Japan, stemming from Japan's military invasion of China since the end of the 18th century. Negative sentiment and racist attitudes against each other exist in public discourses (cf. Lin and Kubota 2011). The interviewees in this study, however, were acutely aware of the harm that racist or prejudiced attitudes cause. For them, looking down upon the local people is a taboo (BM1, AF2, $\mathrm{BF} 1, \mathrm{CF}$ ), and instead, they consider a willingness to collaborate and contribute to the local society to be essential. One former expatriate (AM1) contrasts Japanese attitudes toward Westerners and Asians and states:

In the case of Japan, for example, when we say "gaijin san [foreigner]" we mean white people. And "gaijin" gets "san [polite marker]". ... when we are in Asia, we tend to feel superior ... some people even say Chinese are no good or Thai are no good-they over generalize people.

Becoming critically aware of one's racial and cultural biases, as this statement indicates, constitutes the foundational dispositions.

Cultural knowledge works in tandem with foundational dispositions and communicative dispositions, enabling effective communication. It includes an understanding of the history of China and Japan as well as the historical and political relations between the two. For a current expatriate (AC) for instance, Japan's colonial history in China constitutes essential knowledge; understanding history from "both Japanese point of view and Chinese point of view" provides critical assessment of the legitimacy of a Japanese version. For a former expatriate (BF1), diplomatically and smoothly discussing political conflicts (e.g., the Japanese Prime Minister's visit to Yasukuni Shrine, which enshrines war dead including Japanese war criminals) with his Chinese clients was a challenge. Along with language proficiency, historical knowledge was mentioned by expatriates as what they wished they had before working in China. Interviewees also mentioned cultural expectations such as: face-saving practices that prohibit individual reprimands in public (AF2, BCSubY, BLSubX2); different business practices and protocol, including the interpretation of contract (AF3, BCSubY); and individualism (AC, DM1). Other 
kinds of knowledge of and interests in the host country were regarded to be important as they enable versatile conversations with diverse local workers and clients (AM2, EM, BF1, AC). However, a caveat mentioned was preconceived knowledge; learning about culture and history in pre-departure training could lead to stereotyping (AF3, BCSubY). Talking with colleagues who are already in China, however, could help newcomers avoid this problem.

The second broad category that was mentioned by Japanese interviewees as essential for working overseas had to do with personal qualities. They include, leadership, outgoingness, sociability, bravery, flexibility, perseverance, cooperativeness, broad-mindedness, and mental and physical strength. These qualities, along with other dispositions, help develop effective and respectful communication in cross-cultural contexts.

Success for these manufacturing companies is predicated on producing and selling goods. Thus, distinguished professional competency as an expert in the field is indispensable for success. Equipped with personal qualities and an ability to communicate that is supported by communicative and foundational dispositions and cultural knowledge, expatriates believe that they can manage communicative demands.

\section{Discussion}

This study aimed to understand the nature of communication in non-English-dominant transnational workplaces with pedagogical implications in mind. The findings raise several questions on the following issues: English as an international lingua franca, neoliberal emphasis on developing linguistic skills, and competencies deemed important for border-crossing communication in transcultural work.

\section{Questioning English as an international lingua franca}

First, the findings about Japanese expatriates in China indicate that although English is indeed used as a lingua franca, the use is restricted to certain individuals who engage in tasks involving English-speaking clients locally or internationally or who might have an English-bound linguistic identity due to their previous work experiences in the Englishspeaking world. Instead, Japanese and Mandarin are major languages of workplace communication for the interviewees (cf. Nebashi 2007). Japanese expatriates and Chinese office workers mutually communicate with a range of proficiency in each other's language. As the German study mentioned earlier demonstrates (Amelina 2010), expatriates' use of the language of a non-English-dominant host country and their own native language, rather than English, is not unusual in the transcultural workplace.

This suggests that using ELF, which has attracted great scholarly attention, is only part of lingua franca communication. Thus, research on ELF needs to be situated within a broader framework involving other languages. Many of the communicative strategies mentioned by the participants are also part of plurilingual repertoires that exist across linguistic boundaries (Council of Europe, 2001). This perspective indicates a need to address lingua franca strategies and linguistic diversity in teaching not only English but also diverse L1 and L2.

\section{Critical understanding of the neoliberal emphasis on (English) language skills}

Second, although neoliberal discourse rationalizes the importance of learning English based on the promise that it would provide individual workers with socioeconomic 
benefit, Japanese managers in this study generally viewed skills in English (or any other language) as no more important than professional expertise. Although the managers recognized the importance of English skills in general and Mandarin skills in China, linguistic competency did not override professional competence. Thus, although TOEIC was widely used, it had a more symbolic function of making employees aware of the importance of English skills than a practical role of determining personnel decisions.

Furthermore, it is important to note that none of the expatriates interviewed in this study were women, although the gender imbalance might partly reflect the overall employment pattern in the manufacturing sector in Japan. While English language learning typically attracts female learners, the overrepresentation of male expatriates indicates a gap between the assumption about international mobility that English study is supposed to afford women and the actual opportunities for them in business settings.

\section{Competencies for border-crossing communication}

Third, the competencies required for transcultural work that were mentioned by the interviewees tended to be more about cultural knowledge, communication skills, attitudes, and dispositions than what is strictly linguistic. As discussed above, they can be categorized as ability to communicate, supported by communicative dispositions, foundational dispositions, and cultural knowledge, as well as personal qualities. Also, the expatriates used various strategies to overcome communication challenges. These strategies overlap the strategic competence in the framework of communicative competence (Canale 1983), including paraphrasing to compensate for unlearned linguistic items, using nonverbal strategies, using L1 knowledge (e.g., brush talk), and so on. The expatriates who use the language of the host country manage their communication albeit not perfect. In fact, none of the interviewees mentioned grammatical accuracy or fluency as an important skill for pursuing their work.

These findings indicate that the medium of communication in global work settings might be better described by resources that are partial, simplified, and incomplete and yet effective, rather than a bounded system of what is commonly conceived as language (Blommaert 2010). Should language teaching continue to insist on the conventional emphasis on fluency and accuracy or should it focus more on ability to communicate in real contexts? This question needs to be explored further.

The knowledge, attitudes, and dispositions mentioned by the interviewees also parallel symbolic competence, which is "the ability not only to approximate or appropriate for oneself someone else's language, but to shape the very context in which the language is learned and used" (Kramsch and Whiteside 2008, p. 664). Language users with symbolic competence avoid creating a face-threatening situation for local workers and interact with local people on an equal stance, as partners.

The non-linguistic qualities identified in this study also overlap with many of the general competences in the Common European Framework of Reference for Languages (CEFR) (Council of Europe 2001): namely, declarative knowledge (savoir) of the target society, culture, institutions, and history; skills and know-how (savoir-faire) including social skills, cultural sensitivity, ability to overcome stereotypes; existential competence (savoir-être) including attitudes such as openness, being interested in difference, and exercising cultural relativism in understanding Self and Other as well as motivation and personality; and ability to learn (savoir apprendre) and discover otherness by 
combining other components described above. The non-linguistic qualities identified in this study as well as plurilingualim are already incorporated in this framework of language education.

The general competences described in CEFR can be further complemented by critical cultural awareness/political education (savoir s'engager) as proposed by Byram (1997, 2008). This competence goes beyond the conventional approach to language teaching, which reinforces instrumental pragmatism, the native speaker model, and fixed cultural differences, and instead addresses the awareness that the ways in which social, cultural, and institutional practices operate in diverse cultures and contexts are built upon political, historical, and ideological foundations. It challenges the preconceived notion of what is normal or taken for granted and aims to transform the unequal power relations that exist in learners' consciousness and in social structures. Some of the interviewees' accounts demonstrate their critical awareness or self-reflection of racial and cultural biases, paralleling this dimension.

All in all, the competencies identified in this study constitute knowledge, skills, and dispositions for border-crossing communication, which involves not only English as a lingua franca but also other languages and promotes active, critical and reflective engagement in communication across various kinds of differences (Kubota 2012). Both L1 and L2 classrooms are the sites where these competencies can be developed. It is, however, important to critically reflect on the fact that the competence discussed by CEFR, Byram, and this study is entangled with ideologies of the new economy. This point is discussed in the final section.

\section{Implications for education and policy}

This study provides several educational implications. First, the current rhetoric of the neoliberal promise of English-that proficiency in English as an international lingua franca enables communication universally and that it is indispensable for jobs-should be reconsidered. The study indicates the need to critically reflect on the promise of English, seek to develop dispositional and strategic competencies beyond linguistic accuracy and fluency, and develop willingness to learning languages other than English. In short, it is necessary to develop the awareness that while English proficiency, as understood conventionally, is a necessary condition for many international communicative situations, it is by no means a sufficient condition.

This study also revealed that, despite the perceived importance of language tests like TOEIC for employment opportunities, some employers do not view English proficiency or test scores as more important than professional, personal, and communicative competence. There seems to be a perceptual gap between language educators and transcultural workers. Language educators pursue formal language teaching and assessment to foster sophisticated communicative competence, while transcultural workers acquire and use language in ways quite different from "getting a perfect score on a paper exam.” The language use for real-life purposes (certain job-related tasks in this case) may require quite different kinds of communicative effectiveness. Many transnational workers in this study or the Japanese engineers in the United States (Sunaoshi 2005) who are in the forefront of transcultural work have limited linguistic resources and yet can manage communication. "What constitutes being able to use a language?" is a question to explore further for pedagogical innovation. 
As such notions as ability to communicate and communicative dispositions indicate, such competence is not restricted to a particular language but can be developed and employed across one's linguistic repertoire. Thus, it is necessary to explore how bordercrossing communicative competence-such as how to make oneself understood effectively, how to negotiate linguistic and cultural diversity, and how to affirm differencecould be developed both in L1 and in additional language(s).

\section{Closure: a critical reflection}

The competencies that are required for border-crossing communication identified in this study overlap with those described in CEFR, which has a liberal undertone in its promotion of cultural and linguistic pluralism and dispositional dimensions beyond the language system. Critical cultural awareness (Byram 2008) works in parallel. Also, my analysis of interview accounts questioned and challenged the neoliberal obsession with English and linguistic skills and drew attention to other qualities. Yet, CEFR, Byram's work, or this study cannot escape neoliberalism.

In the case of CEFR, the fact that more attention is paid to the learners' attainment of communicative language competence (linguistic, sociolinguistic, and pragmatic) than other aspects is perhaps a clear indication of its instrumental focus aligned with the development of neoliberal human capital. CEFR's 6-point scale for measuring linguistic competence is even calibrated against the proficiency rating scales of other commercial tests, exacerbating the instrumental focus in language learning (McNamara 2011). CEFR was developed by the Council of Europe, whose mission is to promote human rights, democracy, and rules of law to achieve the economic growth and social cohesion envisioned by the European Union. As Europe is becoming one unified free marketplace, educating students to be able to communicate across cultural and linguistic differences is viewed as fundamental to individual mobility and economic prosperity of the region. Thus, CEFR is inseparable from this regional economic system and ideology.

Critical cultural awareness/political education proposed by Byram $(1997,2008)$ goes further to address more critical dimensions of language study. Yet, the notion of the development of human capital in the knowledge economy is left unquestioned (and even used as a rationale for his proposal) without confronting the problems that neoliberalism has created, including growing non-regular employment, economic gaps between the rich and the poor, and the language divide-namely, the inequality between those who can afford to develop proficiency in a language of power and those who cannot (Block et al. 2012).

Also in this study, although the findings problematize neoliberal assumptions about English and language study as discussed so far, the focus of the study-i.e., large corporate business-is indeed a beneficiary of neoliberalism that supports a free-market economy, promoting global expansion of capital to seek lower production costs and in turn creating economic and consequently educational gaps both domestically and internationally. Furthermore, the ability, dispositions, knowledge, and qualities for bordercrossing communication identified in this study, CEFR, and works by Byram parallel in part the neoliberal educational goals put forth by OECD, such as linguistic skills (e.g., speaking and writing clearly), personal skills (e.g., positive attitudes, adaptability), ability to cope with uncertainty, flexibility, ability to work with others, and learning to learn 
(Hirtt 2009; Hyslop-Margison and Graham 2001; Urciuoli 2010). Would exploring educational implications based on this study be complicit with neoliberalism in late capitalism which has created a great amount of social problems? What would a vision of language education look like in a more critical framework for transforming social, economic, racial, gender, and educational inequalities? What is clear, however, is that border-crossing communication is required not just in transcultural business but also in local communities that are becoming increasingly diverse. More intellectual engagement is needed to resolve these predicaments.

\section{Endnotes}

${ }^{1}$ Throughout the interviews, the term chûgokugo [Chinese language] was used, which refers to Mandarin.

${ }^{2}$ All quotes are translated from Japanese.

Competing interest

The author declares she has no competing interests.

\section{Author's information}

Ryuko Kubota is Professor at the University of British Columbia, Canada. Her research explores critical approaches to second/foreign language education, focusing on such issues as culture, critical multiculturalism, and critical pedagogies. Her articles appeared in such journals as Critical Inquiry in Language Studies, English Journal, Foreign Language Annals, International Journal of Bilingualism and Bilingual Education, Journal of Second Language Writing, Linguistics and Education, L2 Journal, Modern Language Journal, TESOL Quarterly, and World Englishes.

\section{Acknowledgements}

This study was funded by Hampton Fund Research Grant at the University of British Columbia.

Received: 7 May 2013 Accepted: 22 May 2013

Published: 28 May 2013

\section{References}

Amelina, M. 2010. Do other languages than English matter?: International career development of highly-qualified professionals. In Multilingualism at work: From policies to practices in public, medical and business settings, ed. B Meyer and B Apfelbaum, 235-252. Amsterdam: John Benjamins Publishing Company.

Bargiela-Chiappini, F. 2009. Introduction: Business discourse. In The handbook of business discourse, ed. F BargielaChiappini, 1-15. Edinburgh, UK: Edinburgh University Press.

Bloch, B. 1995. Career enhancement through foreign language skills. The International Journal of Career Management. 7(6): 15-26.

Block, D. 2007. Niche lingual francas: An ignored phenomenon. TESOL Q. 41: 561-566.

Block, D, J Gray, and M Holborow. 2012. Neoliberalism and applied linguistics. Abingdon, UK: Routledge.

Blommaert, Y. 2010. The sociolinguistics of globalization. Cambridge, UK: Cambridge University Press.

Blommaert, Y, J Collins, and S Slembrouck. 2005. Spaces of multilingualism. Language \& Communication 25: 197-216.

Butler, YG. 2007. Foreign language education at elementary schools in Japan: Searching for solutions amidst growing diversification. Current Issues in Language Planning 8: 129-147.

Butler, YG, and M lino. 2005. Current Japanese reforms in English language education: The 2003 "Action Plan. Language Policy 4: 25-45.

Byram, M. 1997. Teaching and assessing intercultural communicative competence. Clevedon, UK: Multilingual Matters.

Byram, M. 2008. From foreign language education to education for intercultural citizenship: Essays and reflections. Clevedon, UK: Multilingual Matters.

Canale, M. 1983. From communicative competence to communicative language pedagogy. In Language and communication, ed. JC Richards and RW Schmidt, 2-27. London: Longman.

Council of Europe. 2001. Common European Framework of Reference for Lanquages: Learning, teaching, assessment. Cambridge: Cambridge University Press.

Duff, P. 2008. Language socialization, higher education, and work. In Encyclopedia of language and education, 2nd edition, volume 8: Language socialization, ed. PA Duff and N Hornberger, 257-270. Springer Science + Business Media LLC.

Duff, P, P Wong, and M Early. 2000. Learning language for work and life: The linguistic socialization of immigrant Canadians seeking careers in health care. Can Mod Lang Rev 57: 9-57.

Forey, G, and J Lockwood. 2007. "I'd love to put someone in jail for this": An initial investigation of English in the business processing outsourcing (BPO) industry. Engl. Specif. Purp. 26: 308-326.

Goldstein, T. 1997. Two languages at work: Bilingual life on the production floor. Berlin: Mouton de Gruyter.

Gottlieb, N. 2008. Japan: Language policy and planning in transition. Current Issues Language Planning 9: 1-68.

Graddol, D. 2006. English next: Why global English may mean the end of "English as a Foreign Language. London: British Council. 
Grin, F, C Sfreddo, and F Vaillancourt. 2010. The economics of the multilingual workplace. New York: Routledge. Harper, H, B Peirce, and B Burnaby. 1996. English-in-the-workplace for garment workers: A feminist project? Gend. Educ 8: 5-19.

Heller, M. 2003. Globlization, the new economy, and the commodification of language and identity. J. Socioling. 7: 473-492.

Hirtt, N. 2009. Markets and education in the era of globalized capitalism. In Global neoliberalism and education and its consequences, ed. D Hill and R Kumar, 208-226. New York: Routledge.

Holmes, J. 2003. Power and politeness in the workplace: A sociolinguistic analysis of talk at work. London: Longman.

Hwang, M-J. 2009. Brush talk at the conversation table: Interaction between L1 and L2 speakers of Chinese (doctoral dissertation). Honolulu, HI: University of Hawai'i.

Hyslop-Margison, EJ, and B Graham. 2001. Principles for democratic learning in career education. Can. J. Educ. 26: 341-361.

Jenkins, J, A Cogo, and M Dewey. 2011. Review of developments in research into English as a lingua franca. Lang. Teach. 44: 281-315.

Kachru, Y, and L Smith. 2008. Cultures, contexts and world Englishes. New York: Routledge.

Kawai, Y. 2007. Japanese Nationalism and the global spread of English: An analysis of Japanese governmental and public discourses on English. Language and Intercultural Communication 7: 37-55.

Kirkpatrick, A. 2007. World Englishes: Implications for international communication and English language teaching. Cambridge: UK: Cambridge University Press.

Kramsch, C, and A Whiteside. 2007. Three fundamental concepts in second language acquisition and their relevance in multilingual contexts. Mod Lang J 91: 907-922.

Kramsch, C, and A Whiteside. 2008. Language ecology in multilingual settings. Towards a theory of symbolic competence. Applied Linguistics 29: 645-671.

Kubota, R. 2011. Questioning linguistic instrumentalism: English, neoliberalism, and language tests in Japan. Linguistics and Education 22: 248-260.

Kubota, R. 2012. The politics of ElL: Toward border-crossing communication in and beyond English. In Principles and practices of teaching English as an international language, ed. A Matsuda, 55-69. Bristol, UK: Multilingual Matters.

Kubota, R, and S McKay. 2009. Globalization and language learning in rural Japan: The role of English in the local linguistic ecology. TESOL Q. 43: 593-619.

Lin, A, and R Kubota. 2011. Discourse and race. In The Continuum companion to discourse analysis, ed. K Hyland and B Paltridge, 277-290. Continuum.

Lippi-Green, R. 2012. English with an accent: Language, ideology, and discrimination in the United States, 2nd ed. London and New York: Routledge.

Matsuura, H, M Fujieda, and S Mahoney. 2004. The officialization of English and ELT in Japan: 2000. World Englishes. 23: 471-487.

McKay, SL, and WD Bokhorst-Heng. 2008. International English in its sociolinguistic contexts: Towards a socially sensitive ElL pedagogy. New York: Routledge.

McNamara, T. 2011. Managing learning: Authority and language assessment. Lang. Teach. 44: 500-515.

2003. MEXT (Ministry of Education, Culture, Sports, Science and Technology). Action plan to cultivate "Japanese with English abilities.". Retrieved December 19, 2011 from http://www.mext.go.jp/b_menu/shingi/chukyo/chukyo4/007/ gijiroku/03032401/009.pdf.

Mufwene, SS. 2010. Globalization, global English, and world English(es): Myths and facts. In The handbook of language and globalization, ed. N Coupland, 31-55. Malden, MA: Wiley.

Nakatani, Y. 2005. The effects of awareness-raising training on oral communication strategy use. Mod. Lang. J. 89: 76-91.

Nebashi, R. 2007. Chûgoku shinshutsu nikkei kigyô ni oite jûgyôin ga konnan o kanjite ita kôdô: Mensetsu chôsa no jiyû kaitô bunseki kara [Behaviors perceived challenging by employees at Japanese companies in China: Analysis of open-ended responses in structured interviews]. In Beikoku Chûgoku shinshutsu nikkei kigyô ni okeru ibunkakan comyunikêshon masatsu [Intercultural communication conflicts at Japanese companies in the United States and China], ed. H Nishida, 439-461. Tokyo: Kazama Shobô.

Nieto, S, and P Bode. 2008. Affirming diversity: The socio-political context of multicultural education, 5th ed. Boston: Allyn \& Bacon.

Norton, B. 2000. Identity and language learning: Gender, ethnicity and educational change. London: Longman.

Park, JS-Y. 2010. Naturalization of competence and the neoliberal subject: Success stories of English language learning in the Korean conservative press. J Linguistic Anthropology 20: 22-38.

Park, JS-Y. 2011. The promise of English: Linguistic capital and the neoliberal worker in the South Korean job market. Int J Bilingual Education and Bilingualism 14: 443-455.

Phillipson, R. 2009. Linguistic imperialism continued. New York and London: Routledge.

Piekkari, R. 2008. Language and careers in multinational corporations. In International management and language, ed. S Tietze, 128-137. London: Routledge.

Piekkari, R. 2009. International management. In The handbook of business discourse, ed. F Bargiela-Chiappini, 269-278. Edinburgh, UK: Edinburgh University Press.

Roberts, C. 2007. Multilingualism in the workplace. In Handbook of multilingualism and multilingual communication, ed. P Auer and L Wei, 405-422. Berlin and New York: Mouton de Gruyter.

Rogerson-Revell, P. 2007. Using English for international business: A European case study. Engl. Specif. Purp. 26: 103-120

Rogerson-Revell, P. 2008. Participation and performance in international business meetings. Engl. Specif. Purp. 27: 338-360

Seidlhofer, B. 2011. Understanding English as a lingua franca. Oxford: Oxford University Press.

Sharifian, F (ed.). 2009. English as an international language: Perspectives and pedagogical issues. Bristol, UK: Multilingual Matters.

Skutnabb-Kangas, T. 2000. Linguistic genocide in education Or worldwide diversity and human rights? Mahwah, NJ: Lawrence Erlbaum Associates.

Sunaoshi, Y. 2005. Historical context and intercultural communication: Interactions between Japanese and American factory workers in the American South. Lang. Soc. 34: 185-217. 
Tanaka, H. 2009. Japan. In The handbook of business discourse, ed. F Bargiela-Chiappini, 332-344. Edinburgh, UK Edinburgh University Press.

Toyo Keisai 2009. Kaigai shinshutsu kigyô: Kuni betsu hen [Companies overseas: Country version]. Tokyo: Tôyô Keizai Shinpô Sha. Urciuoli, B. 2008. Skills and selves in the new workplace. Am. Ethnol. 35: 211-228.

Urciuoli, B. 2010. Neoliberal education: Preparing the student for the new workplace. In Ethonographies of neoliberalism, ed. CJ Greenhouse, 162-176. Philadelphia, PA: University of Pennsylvania Press.

Williams, G. 2010. The knowledge economy, language and culture. Bristol, UK: Multilingual Matters.

Wozniak, S. 2010. Language needs analysis from a perspective of international professional mobility: The case of French mountain guides. Engl. Specif. Purp. 29: 243-252.

doi:10.1186/2191-5059-3-4

Cite this article as: Kubota: 'Language is only a tool': Japanese expatriates working in China and implications for language teaching. Multilingual Education 2013 3:4.

\section{Submit your manuscript to a SpringerOpen ${ }^{\circ}$ journal and benefit from:}

- Convenient online submission

Rigorous peer review

- Immediate publication on acceptance

- Open access: articles freely available online

- High visibility within the field

Retaining the copyright to your article

Submit your next manuscript at $\boldsymbol{\sim}$ springeropen.com 